\title{
Effect of everolimus rescue therapy for acute cellular rejection following pediatric living donor liver transplantation: Report of one case
}

\author{
Shin Hwang ${ }^{1}$, Jung-Man Namgoong ${ }^{2}$, Seak Hee $\mathrm{Oh}^{3}$, Kyung Mo Kim ${ }^{3}$, \\ Chul-Soo Ahn ${ }^{1}$, Hyunhee Kwon ${ }^{2}$, Yu Jeong $\mathrm{Cho}^{2}$, and Yong Jae Kwon ${ }^{2}$ \\ ${ }^{1}$ Division of Hepatobiliary Surgery and Liver Transplantation, Department of Surgery, Asan Medical Center, \\ University of Ulsan College of Medicine, ${ }^{2}$ Division of Pediatric Surgery, Department of Surgery, \\ Asan Medical Center, University of Ulsan College of Medicine, ${ }^{3}$ Department of Pediatrics, Asan Medical Center, \\ University of Ulsan College of Medicine, Seoul, Korea

\begin{abstract}
Acute cellular rejection (ACR) after pediatric living donor liver transplantation (LDLT) is often curable with steroid pulse therapy, but a few pediatric patients show steroid-resistant ACR, which is difficult to control. We report the effect of everolimus as a rescue therapy for ACR in a case of pediatric LDLT. The patient was a 11-year-old girl who was admitted due to subacute liver failure of unknown cause. LDLT operation using a modified right liver graft from her mother was performed. The graft-recipient weight ratio was 1.30. The explant liver showed massive hepatic necrosis. The patient recovered uneventfully with immunosuppression using tacrolimus and low-dose steroid. However, at postoperative day (POD) 20, the liver enzyme levels began to increase. The first liver biopsy taken at POD 25 showed moderate ACR with rejection activity index (RAI) score of 7 . At that time, steroid pulse therapy was performed, but the patient did not respond and the liver enzyme levels increased further. The second liver biopsy taken at POD 40 showed moderate ACR with RAl score of 7 . At this time, everolimus was administered, and soon after that, liver enzyme levels had gradually improved. Currently, the patient is doing well for 44 months to date without any abnormal findings. The maintenance target trough concentrations were tacrolimus $5 \mathrm{ng} / \mathrm{ml}$ and everolimus $3 \mathrm{ng} / \mathrm{ml}$. Our case demonstrated the effect of rescue therapy using everolimus for ACR following pediatric LDLT. Further studies are needed to assess the role of everolimus in pediatric liver transplant recipients suffering from ACR. (Ann Hepatobiliary Pancreat Surg 2020;24:216-220)
\end{abstract}

Key Words: Acute cellular rejection; Rescue therapy; Immunosuppression; Everolimus; Sirolimus

\section{INTRODUCTION}

The prognosis of pediatric living donor liver transplantation (LDLT) is quite favorable, but a variety of graft rejections can develop at any time as like in the cases of adult liver transplantation (LT). It is noted that acute cellular rejection (ACR) after pediatric LDLT is often curable with administration of high-dose steroid pulse therapy, but a few pediatric patients show steroid-resistant ACR, which is known to be difficult to control and can be led to graft failure for this reason.

Everolimus, which is a mammalian target of rapamycin (mTOR) inhibitor, is a derivative of sirolimus with a sim- ilar mechanism of action. Sirolimus is a macrocyclic triene antibiotic that was initially found to have antifungal properties, but may also act as a primary immunosuppressant or antitumor agent. ${ }^{1}$ According the social health insurance policy in Korea, sirolimus is currently permissible to use for kidney transplantation and everolimus is permissible only for utilization with liver, heart and intestine transplantations. However, the safety and benefit of using everolimus in pediatric LT patients are not well known yet, although there are sporadic reports on pediatric cases using everolimus worldwide. Calcineurin inhibitor (CNI) inhibits calcium-dependent T-cell activation. ${ }^{2}$ In contrast, mTOR inhibitor acts on B cells independently of their ef-

Received: March 18, 2020; Revised: March 22, 2020; Accepted: March 23, 2020

Corresponding author: Shin Hwang

Department of Surgery, Asan Medical Center, University of Ulsan College of Medicine, 88 Olympic-ro 43-gil, Songpa-gu, Seoul 05505, Korea Tel: +82-2-3010-3930, Fax: +82-2-3010-6701, E-mail: shwang@amc.seoul.kr

Copyright (C) 2020 by The Korean Association of Hepato-Biliary-Pancreatic Surgery

This is an Open Access article distributed under the terms of the Creative Commons Attribution Non-Commercial License (http://creativecommons.org/ licenses/by-nc/4.0) which permits unrestricted non-commercial use, distribution, and reproduction in any medium, provided the original work is properly cited. Annals of Hepato-Biliary-Pancreatic Surgery • pISSN: 2508-5778 - elSSN: 2508-5859 
fects on helper $\mathrm{T}$ cells, resulting in inhibition of antigenand cytokine-driven $\mathrm{B}$ cell proliferation. ${ }^{3}$ There are many data demonstrating the valuable effects of mTOR inhibitors in adult solid organ transplant recipients. ${ }^{4-8}$ The synergism in efficacy between CNIs and mTOR inhibitors also allows significant reduction in CNI dosage. ${ }^{9,10}$ Because of such different modes of action, mTOR inhibitors have been used for control of refractory rejections in adult LT recipients. ${ }^{11,12}$ However, it is noted that there are only a few cases of pediatric LT cases using mTOR inhibitors for chronic rejection. ${ }^{13}$

Here we report the effect of everolimus as a rescue therapy for ACR in a case of pediatric LDLT.

\section{CASE}

The patient is a 11-year-old girl who was admitted due to having experienced jaundice for 2 months. Her initial blood laboratory findings were aspartate aminotransferase (AST) 508 IU/L, alanine aminotransferase (ALT) 434 IU/L, total bilirubin $20.5 \mathrm{mg} / \mathrm{dl}$, direct bilirubin 15.5 $\mathrm{mg} / \mathrm{dl}$, and prothrombin time INR 2.11. After full work-up, she was finally diagnosed of acute liver failure of unknown cause (Fig. 1). The patient's liver function did not recover despite being given the best supportive care for 20 days, thus LDLT operation was planned at that juncture.

The donor was the patient's mother. Since the patient weighed $44 \mathrm{~kg}$, a modified right liver graft weighing 570 $\mathrm{g}$ was implanted according to the standard procedures of LDLT (Fig. 2A). The graft-recipient weight ratio was 1.30. Biliary reconstruction was performed through ductto-duct anastomosis (Fig. 2B). The explant liver showed massive hepatic necrosis without portal inflammation (Fig.
3). The patient recovered uneventfully with immunosuppression using tacrolimus and low-dose steroid.

However, in this case, the liver enzymes began to increase after postoperative day (POD) 20. At POD 25, AST was raised to $457 \mathrm{IU} / \mathrm{L}$, and thus a percutaneous liver biopsy was performed. The liver biopsy findings were as follows: moderate portal tract inflammation; endothelialitis with lymphocyte infiltration at perivenular hepatic parenchyma; multifocal hepatocyte apoptosis; and moderate lobular activity. These results were consistent with moderate ACR with a rejection activity index (RAI) score of 7. Steroid pulse therapy was performed, but the patient did not respond and liver enzyme levels increased further, reaching AST 1,024 IU/L at POD 40. Dynamic computed tomography scan showed swelling of the liver graft without vascular complications (Fig. 4). Additionally, the sec-

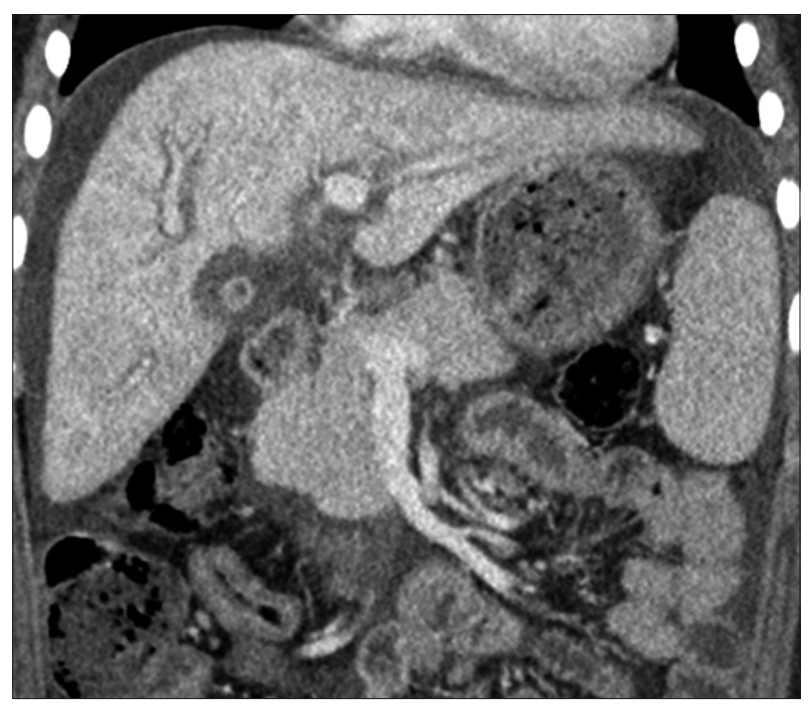

Fig. 1. Pretransplant computed tomography finding. The liver was shrunken and liver perfusion was impaired, suggesting a failing liver.
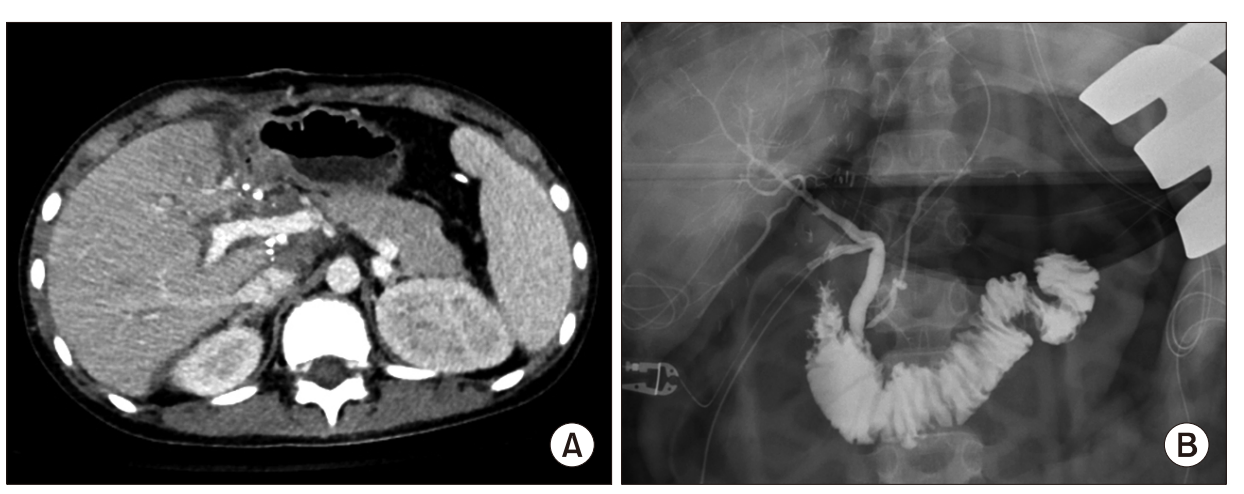

Fig. 2. Posttransplant findings. (A) Computed tomography scan taken 7 days after transplantation showed no abnormal findings. (B) Intraoperative cholangiogram showed uneventful duct-to-duct anastomosis. 


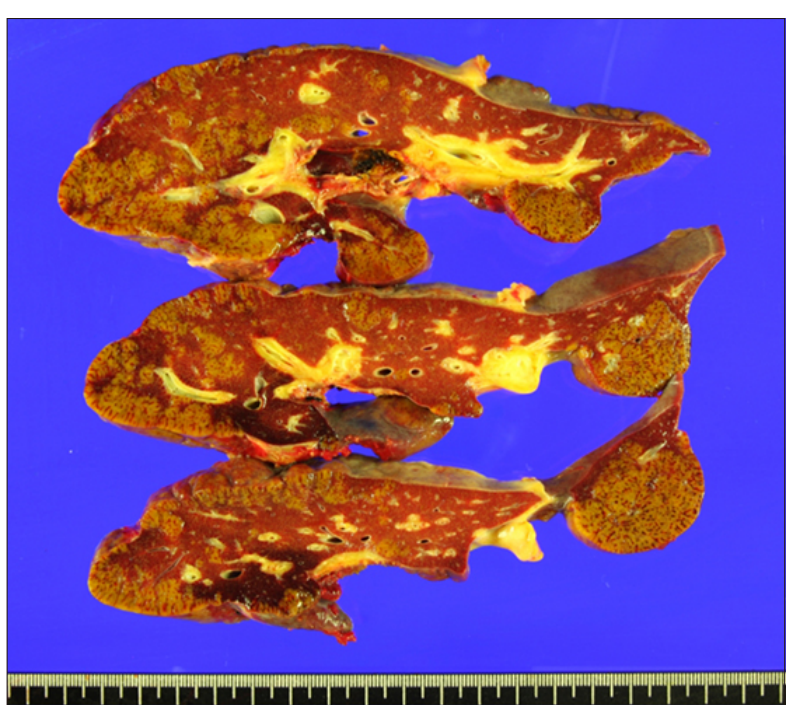

Fig. 3. Gross photograph of the explant liver. Massive hepatic necrosis was visible.

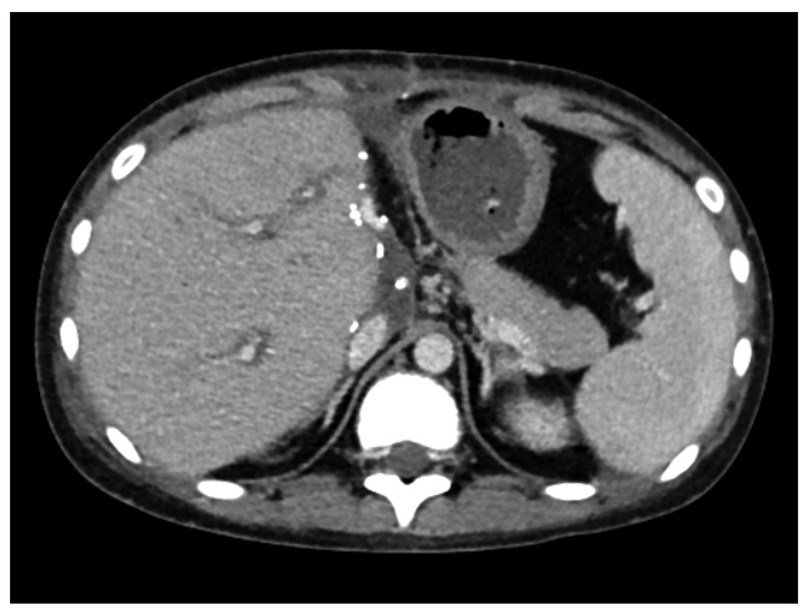

Fig. 4. Posttransplant computed tomography findings. Computed tomography scan taken 49 days after transplantation showed swelling of the liver graft, suggesting acute rejection.

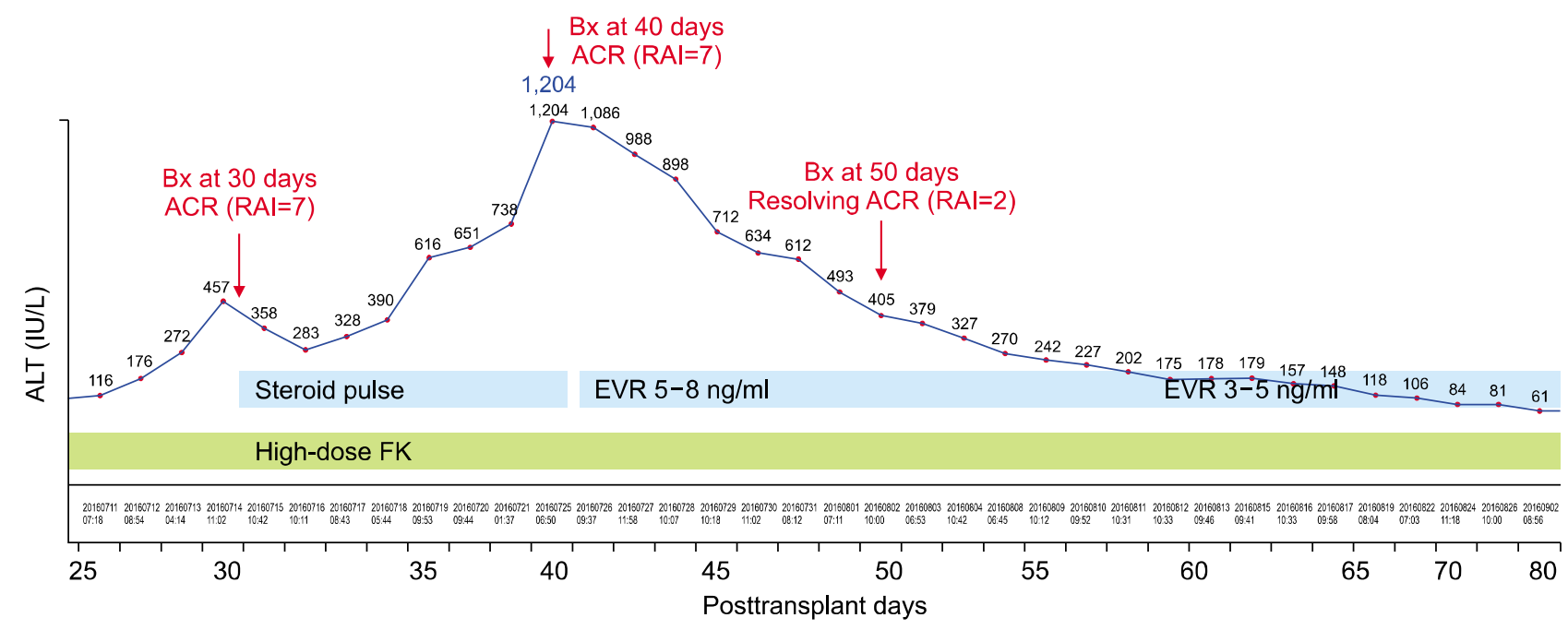

Fig. 5. Serial changes of clinical sequences around the episode of acute cellular rejection. ALT, alanine aminotransferase; Bx, liver biopsy; RAI, rejection activity index; ACR, acute cellular rejection; FK, tacrolimus; EVR, everolimus.

ond liver biopsy showed severe portal tract inflammation, moderate bile duct damage, moderate endothelialitis, and perivenular hepatocyte dropout. These results were also consistent with moderate ACR with a RAI score of 7 .

At this time, everolimus was administered as a rescue therapy to treat ACR. The initial target trough concentration of everolimus was $5-8 \mathrm{ng} / \mathrm{ml}$. Soon after that, liver enzymes had gradually improved. At POD 50, the third liver biopsy was performed, in which there were mild portal tract inflammation, mild bile duct damage, mild canalicular and cholangiolar cholecystitis, and mild perivenular fibrosis and perisinusoidal and portal fibrosis. These were also consistent with resolving ACR with a RAI score of 2. Thereafter, the maintenance target trough concentration of everolimus was set to be $3-5 \mathrm{ng} / \mathrm{ml}$. The serial changes of these clinical sequences were depicted at Fig. 5.

Currently, the patient is doing well for 44 months to date without any abnormal findings. The maintenance target trough concentrations were tacrolimus $5 \mathrm{ng} / \mathrm{ml}$ and everolimus $3 \mathrm{ng} / \mathrm{ml}$.

\section{DISCUSSION}

The mTOR inhibitor is an immunosuppressant that in- 
terrupts the interleukin-2 proliferative response cascade and has dual inhibitory effects on cell growth and angiogenesis. mTOR inhibitor is increasingly administered as indicated for renal dysfunction or malignancy. The use of everolimus has been financially covered by the social health insurance in Korea since early $2016 .{ }^{14}$ Everolimus can be administer after first 1 month of LT primarily because of the potential risk of hepatic artery thrombosis and wound healing problems. However, everolimus is permissible to adult LT recipients in Korea and not yet to pediatric LT recipients. This is one of the main reasons why we presented this case.

Bilbao et al. ${ }^{11}$ reported that, as reviewed in 74 adult LT recipients, the causes of conversion to everolimus were reported to be refractory rejection in $31.1 \%$, extended hepatocellular carcinoma in the explanted liver in $19 \%$, hepatocellular carcinoma recurrence during follow-up in $8.1 \%$, de novo tumor in $17.6 \%$, CNI-related neurotoxicity in $10.8 \%$, renal dysfunction in $8.1 \%$, and others in $5.4 \%$. They also reported that $73.9 \%$ of the refractory rejection cases were resolved after everolimus administration. When everolimus was used to treat refractory rejection $(n=23)$, the event was resolved correctly in 17 patients $(73.9 \%)$. The remaining six patients failed to respond: four progressed to severe chronic refractory rejection finally requiring retransplantation and two died, one due to sepsis and one from concomitant severe hepatitis $\mathrm{C}$ recurrence.

Ueno et al. ${ }^{13}$ also reported that chronic rejection in two pediatric LT recipients, in whom liver function tests were stable with no progression of liver biopsy fibrosis after everolimus administration. However, regarding the effect of everolimus on ACR in pediatric LT recipients, there was no report in the literature to our knowledge on this issue.

In Korea, everolimus is not permissible in pediatric LT recipients primarily due to the lack of information on safety of its administration, thus it has been rarely administered as a primary immunosuppressant to pediatric recipients. Nielsen et al. ${ }^{15}$ reported the first results using everolimus as a rescue therapy in pediatric LT recipients for the following indications: chronic graft dysfunction in 12 , suspected CNI toxicity in 3 , hepatoblastoma in 2 , and recurrence of primary sclerosing cholangitis posttransplant in 1 . They reported that four patients with chronic graft dysfunction recovered completely normal liver function tests using everolimus, six patients showed partial improvement, and two patients did not respond at all.

Worldwide, it is noted that administration of everolimus to pediatric LT recipients was reported from Germany by Nielsen et al. ${ }^{15}$ and Ganschow, ${ }^{16}$ France by Dumortier et al., ${ }^{17}$ Japan by Ueno et al., ${ }^{13}$ and in an international study from Germany, Sweden, United Kingdom and United States by Ganschow et al. ${ }^{18}$ With worldwide accumulation of experience of everolimus use in pediatric $\mathrm{LT}$ recipients, it is reasonable to permit everolimus administration for pediatric recipients by the Korea Ministry of Food and Drug Safety. However, many well-known side-effects and other published side effects of everolimus must be taken into account when administering everolimus to children and adolescents, namely they can experience the incidences of nausea and diarrhea, hematologic changes, and impaired fertility. ${ }^{9,19,20}$

In conclusion, our case demonstrated the effect of rescue therapy using everolimus for ACR following pediatric LDLT. Further studies are needed to assess the role of everolimus in pediatric LT recipients suffering from ACR, and the appropriateness of this treatment going forward for pediatric patient populations.

\section{CONFLICT OF INTEREST}

None of the authors have any conflict of interest.

\section{ORCID}

Shin Hwang: https://orcid.org/0000-0002-9045-2531

Jung-Man Namgoong:

https://orcid.org/0000-0002-9237-7440

Seak Hee Oh: https://orcid.org/0000-0002-9672-8877

Kyung Mo Kim: https://orcid.org/0000-0001-7896-6751

Chul-Soo Ahn: https://orcid.org/0000-0002-3844-3646

Hyunhee Kwon: https://orcid.org/0000-0001-6647-9155

Yu Jeong Cho: https://orcid.org/0000-0001-6823-2746

Yong Jae Kwon: https://orcid.org/0000-0001-9490-1229

\section{AUTHOR CONTRIBUTIONS}

Conceptualization: SH. Data curation: SHO, KMK, CSA, HK, YJC, YJK. Visualization: SH, JMN. Writing - 
original draft: SH, JMN. Writing - review \& editing: SH.

\section{REFERENCES}

1. Calne RY, Collier DS, Lim S, Pollard SG, Samaan A, White DJ, et al. Rapamycin for immunosuppression in organ allografting. Lancet 1989;2:227.

2. Flanagan WM, Corthésy B, Bram RJ, Crabtree GR. Nuclear association of a T-cell transcription factor blocked by FK-506 and cyclosporin A. Nature 1991;352:803-807.

3. Aagaard-Tillery KM, Jelinek DF. Inhibition of human B lymphocyte cell cycle progression and differentiation by rapamycin. Cell Immunol 1994;156:493-507.

4. Holdaas H, Bentdal O, Pfeffer P, Mjørnstedt L, Solbu D, Midtvedt K. Early, abrupt conversion of de novo renal transplant patients from cyclosporine to everolimus: results of a pilot study. Clin Transplant 2008;22:366-371.

5. De Simone P, Nevens F, De Carlis L, Metselaar HJ, Beckebaum S, Saliba F, et al.; H2304 Study Group. Everolimus with reduced tacrolimus improves renal function in de novo liver transplant recipients: a randomized controlled trial. Am J Transplant 2012; 12:3008-3020.

6. Nashan B. mTOR inhibition and clinical transplantation: liver. Transplantation 2018;102(2S Suppl 1):S19-S26.

7. Levy G, Schmidli H, Punch J, Tuttle-Newhall E, Mayer D, Neuhaus P, et al. Safety, tolerability, and efficacy of everolimus in de novo liver transplant recipients: 12- and 36-month results. Liver Transpl 2006;12:1640-1648.

8. De Simone P, Carrai P, Precisi A, Petruccelli S, Baldoni L, Balzano E, et al. Conversion to everolimus monotherapy in maintenance liver transplantation: feasibility, safety, and impact on renal function. Transpl Int 2009;22:279-286.

9. Saliba F, De Simone P, Nevens F, De Carlis L, Metselaar HJ, Beckebaum S, et al.; H2304 Study Group. Renal function at two years in liver transplant patients receiving everolimus: results of a randomized, multicenter study. Am J Transplant 2013;13: 1734-1745.

10. Fischer L, Saliba F, Kaiser GM, De Carlis L, Metselaar HJ, De Simone P, et al.; H2304 Study Group. Three-year outcomes in de novo liver transplant patients receiving everolimus with reduced tacrolimus: follow-up results from a randomized, multicenter study. Transplantation 2015;99:1455-1462.

11. Bilbao I, Dopazo C, Lazaro J, Castells L, Caralt M, Sapisochin $\mathrm{G}$, et al. Multiple indications for everolimus after liver transplantation in current clinical practice. World J Transplant 2014; 4:122-132.

12. Mártinez JM, Pulido LB, Bellido CB, Usero DD, Aguilar LT, Moreno JL, et al. Rescue immunosuppression with mammalian target of rapamycin inhibitor drugs in liver transplantation. Transplant Proc 2010;42:641-643.

13. Ueno T, Hiwatashi S, Saka R, Yamanaka H, Takama Y, Tazuke $\mathrm{Y}$, et al. Everolimus rescue treatment for chronic rejection after pediatric living donor liver transplantation: 2 case reports. Transplant Proc 2018;50:2872-2876.

14. Kang SH, Hwang S, Ha TY, Song GW, Jung DH, Ahn CS, et al. Cross-sectional analysis of immunosuppressive regimens focused on everolimus after liver transplantation in a Korean highvolume transplantation center. Korean J Transplant 2019;33:98-105.

15. Nielsen D, Briem-Richter A, Sornsakrin M, Fischer L, Nashan B, Ganschow R. The use of everolimus in pediatric liver transplant recipients: first experience in a single center. Pediatr Transplant 2011;15:510-514.

16. Ganschow R, Pape L, Sturm E, Bauer J, Melter M, Gerner P, et al. Growing experience with mTOR inhibitors in pediatric solid organ transplantation. Pediatr Transplant 2013;17:694-706.

17. Dumortier J, Couchonnal E, Lacaille F, Rivet C, Debray D, Boillot $\mathrm{O}$, et al. mTOR inhibitors in pediatric liver transplant recipients. Clin Res Hepatol Gastroenterol 2019;43:403-409.

18. Ganschow R, Ericzon BG, Dhawan A, Sharif K, Martzloff ED, Rauer B, et al. Everolimus and reduced calcineurin inhibitor therapy in pediatric liver transplant recipients: results from a multicenter, prospective study. Pediatr Transplant 2017;21.

19. Lehmkuhl HB, Mai D, Dandel M, Knosalla C, Hiemann NE, Grauhan $\mathrm{O}$, et al. Observational study with everolimus (Certican) in combination with low-dose cyclosporine in de novo heart transplant recipients. J Heart Lung Transplant 2007;26:700-704.

20. Pascual J, Boletis IN, Campistol JM. Everolimus (Certican) in renal transplantation: a review of clinical trial data, current usage, and future directions. Transplant Rev 2006:20:1-18. 